University of Rhode Island

DigitalCommons@URI

Cancer Prevention Research Center Faculty

Publications

Cancer Prevention Research Center

2010

\title{
Validation of a Measure to Assess Alcohol- and Marijuana-Related Risks and Consequences Among Incarcerated Adolescents
}

\author{
L.A.R. Stein \\ University of Rhode Island, larstein@uri.edu \\ Rebecca Lebeau \\ University of Rhode Island, rlc03@uri.edu \\ Mary Clair \\ Joseph S. Rossi \\ University of Rhode Island, jsrossi@uri.edu \\ Rose Marie Martin
}

See next page for additional authors

Follow this and additional works at: https://digitalcommons.uri.edu/cprc_facpubs

Terms of Use

All rights reserved under copyright.

\section{Citation/Publisher Attribution}

Stein, L. A. R., Lebeasu, R., Clair, M., Rossi, J. S., Martin, R.M., \& Golembeske, C. (2010). Validation of a Measure to Assess Alcohol- and Marijuana-Related Risks and Consequences Among Incarcerated Adolescents. Drug Alcohol Dependence, 109(1-3), 104-113. doi: 10.1016/j.drugalcdep.2009.12.015 Available at: http://www.dx.doi.org/10.1016/j.drugalcdep.2009.12.015

This Article is brought to you for free and open access by the Cancer Prevention Research Center at DigitalCommons@URI. It has been accepted for inclusion in Cancer Prevention Research Center Faculty Publications by an authorized administrator of DigitalCommons@URI. For more information, please contact digitalcommons-group@uri.edu. 


\section{Authors}

L.A.R. Stein, Rebecca Lebeau, Mary Clair, Joseph S. Rossi, Rose Marie Martin, and Charles Golembeske

This article is available at DigitalCommons@URI: https://digitalcommons.uri.edu/cprc_facpubs/8 


\title{
Validation of a Measure to Assess Alcohol- and Marijuana-Related Risks and Consequences Among Incarcerated Adolescents*
}

\author{
L.A.R. Stein ${ }^{a, b, c}$, Rebecca Lebeau ${ }^{a}$, Mary Clairb,c, Joseph S. Rossi $^{\mathrm{a}}$, Rose Marie Martin ${ }^{\mathrm{C}}$, \\ and Charles Golembeske ${ }^{b}$ \\ aSocial Sciences Research Center, University of Rhode Island, 2 Chafee Road, Kingston, RI 02881 \\ bThe Rhode Island Training School, Juvenile Correctional Services, 300 New London Avenue, \\ Cranston, RI 02920 \\ ${ }^{\circ}$ Center for Alcohol and Addiction Studies, Brown University 121 South Main Street, Providence, RI \\ 02906
}

\begin{abstract}
Few measures exist to assess risky behaviors and consequences as they relate to substance use in juvenile delinquents. This study sought to validate such a measure on a racially and ethnically diverse sample $(\underline{N}=175)$. Results indicate that alcohol-related risky behaviors and consequences comprise a single scale as do marijuana-related risky behaviors and consequences. Furthermore, results suggest that the retention of common items for both scales produces reliable and valid scales and maintains parsimony. Internal consistencies were more than adequate $(0.72-0.83)$ and test-retest stabilities, even across several months were acceptable $(0.52$ - 0.50). The scales evidenced a high degree of concurrent and predictive incremental validity in predicting conduct disorder, dependence symptoms, and consumption patterns. Researchers can use these scales to measure a generalized construct tapping risks and consequences as related to alcohol and marijuana use. Ease of use may make these scales appealing to clinicians who can provide feedback to clients regarding risky behaviors involving alcohol and marijuana.
\end{abstract}

\section{Keywords}

Substance-related consequences; adolescence; delinquents

\section{Introduction}

\begin{abstract}
Marijuana and alcohol are widely used substances among adolescents beginning as early as middle school. Recent national surveys found lifetime alcohol consumption in middle school adolescents to be as high as $66 \%$ among $8^{\text {th }}$ graders and $74 \%$ among high school adolescents (Eaton, Kann, Kinchen, Ross, Hawkins, Harris, et al., 2006; Whalen, Grunbaum, Kinchen, McManus, Shanklin, Kann et al., 2006). Similarly, marijuana lifetime use for $8^{\text {th }}$ graders was reported as high as $25 \%$ while $38 \%$ of high school students report lifetime marijuana use (Eaton

\footnotetext{
*A copy of the questionnaire is available with the online version of the paper at doi:xxx/j.drugalcdep.xxx... Corresponding Author: Dr. L.A.R. Stein, Social Sciences Research Center, Chafee Rd., Kingston, RI 02881, T: 401-874-4261, F: 401-874-5562 LARStein@uri.edu.

Publisher's Disclaimer: This is a PDF file of an unedited manuscript that has been accepted for publication. As a service to our customers we are providing this early version of the manuscript. The manuscript will undergo copyediting, typesetting, and review of the resulting proof before it is published in its final citable form. Please note that during the production process errors may be discovered which could affect the content, and all legal disclaimers that apply to the journal pertain.
} 
et al., 2006; Whalen et al., 2006). Incarcerated adolescents have even higher rates of substance use. A recent investigation of substance use by adolescents in the juvenile justice systems found adolescents arrested in the past year were twice as likely to have used alcohol and 3.5 times more likely to have used marijuana as compared to adolescents who were not arrested in the last year (National Center on Addiction and Substance Abuse at Columbia University, 2004). Alcohol and marijuana are the two most frequently used substances among adolescent detainees (McClelland, Elkington, Teplin, Abram, 2004).

In addition to using substances, adolescence is also a time of engaging in a variety of risky behaviors, including drinking and driving, risky sex, and other behaviors leading to injury (e.g., fighting). For example, 29\% of high school adolescents nationwide (Eaton et al., 2006) and $45 \%$ of students from a rural, southern middle school reported being a passenger in a car with someone who had been drinking alcohol during the past month (Muilenburg, Johnson, Usdan, Annang, \& Clayton, 2007). Ten percent of high school students nationwide (Eaton et al., 2006) and $17 \%$ of rural, southern middle school students had driven a motor vehicle after consuming alcohol (Muilenburg et al., 2007).

When compared to non-arrestees, adolescent arrestees reported more substance use, unprotected sexual acts, substance use during sex (both self and partner), and diagnoses of sexually transmitted infections (Tolou-Shams, Brown, Gordon, \& Fernandez, 2007). One recent study found $98 \%$ of adolescents with substance use disorders were sexually active and $77 \%$ had multiple partners within the past 3 months (Teplin, Elkington, McClelland, Abram, Mericle, \& Washburn, 2005). When engaging in casual sex (i.e., sex with someone not known well) and unprotected sex, substance use plays a large role for incarcerated adolescents. Sixtythree percent of adolescents reported always using marijuana when engaging in sex with someone they did not know well and $40 \%$ indicated always using alcohol when having casual sex (Rosengard, Stein, Barnett, Monti, Golembeske, \& Lebeau-Craven, 2006). Moreover, 46\% of adolescents always used marijuana and $15 \%$ of adolescents always drank alcohol when unprotected sex was practiced (Rosengard et al, 2006).

Adolescents also sustain significant injuries while under the influence of substances (Spirito, Rasile, Vinnick, Jelalian \& Arrigan, 1997) with adolescents with a behavior disorder 9.4 times more at risk for injuries as compared to peers without behavior disorders (Riley, Harris, Ensminger, Ryan, Alexander, Green, et al, 1996). There is also a link between behavior disorders and substance use with findings indicating that $28 \%$ of those diagnosed with a substance use disorder at age 18 also have a behavior disorder (Lansford, Erath, Yu, et al, 2008). With rates of alcohol and marijuana use disorders high among adolescent detainees (26 $\%$ and $43 \%$, respectively; Teplin, Abram, McClelland et al, 2002), and the high proportion of incarcerated adolescents (over 86\%; Stein, Hesselbrock \& Bukstein, 2008) diagnosed with a behavior disorder, this population is at high risk for injuries.

Given the high prevalence of alcohol and marijuana use among adolescents and the impact it has on risky behaviors, especially among adolescents involved with the juvenile justice system, it is imperative that psychometrically sound instruments are available for this population.

However, despite the need, there is a dearth of instruments that measure alcohol and marijuana use and risky behaviors for this population. Instruments exist to assess alcohol and drug use such as the Customary Drinking and Drug Use Record (Brown, Myers, Lippke, Tapert, Stewart, \& Vik, 1998) and the Teen-Addictions Severity Index (Kaminer, Bukstein, \& Tarter, 1991). There are also adolescent instruments that assess marijuana and alcohol use and related negative consequences and problems, including the Rutgers Alcohol Problem Index (RAPI; White \& Labouvie, 1989), the Rutgers Marijuana Problem Index (RMPI; Johnson \& White, 1989), and the Adolescent Cannabis Problems Questionnaire (CPQ-A; Copeland, Gilmore, Gates, \& Swift, 2005). These instruments assess substance-related behaviors putting 
adolescents at risk for poor outcome (going to school while high/drunk), they assess problembehavior associated with substance acquisition (pawning belongings), and they assess negative consequences (becoming ill, legal trouble).

In addition, longer and more comprehensive instruments exist to evaluate substance use along with other potential problem areas for adolescents. These include the Personal Experiences Inventory (PEI; Winters \& Henly, 1989) which is comprised of two parts, the Problems Severity section (153 questions) and the Psychosocial section (147 questions); and the 139item Problem Oriented Screening Instrument for Teenagers (POSIT; Rahdert, 1991), which assesses 10 problem areas: Substance use, physical health, mental health, family relations, peer relationships, educational status, vocations status, social skills, leisure and recreation, and aggressive behavior/delinquency.

Although longer instruments like the POSIT and PEI have been used with delinquent populations (Dembo, Schmeidler, Borden, Sue \& Manning, 1997; Latimer, Winters \& Stinchfield, 1997), in general the above measures have been validated and used in general and clinical adolescent populations. Well-validated, briefer measures, developed in ethnically diverse samples of juvenile delinquents are needed to assist in assessment and treatment planning. As Winters (2004) indicates, many of the substance use instruments lack important validity data among subpopulations of adolescents (i.e., identified by race, ethnicity, age, and/ or type of setting) indicating that an instrument that is validated on a racially and ethnically diverse population of incarcerated adolescents would add to the existing resources. Moreover, none of the above instruments have been validated using incremental validity. Incremental validity addresses whether a measure adds to the prediction of a criterion above what can be predicted by other sources of data. A number of investigators over the decades have indicated that newly developed tests should demonstrate an ability to add to the prediction of outcomes beyond that which was possible with other available strategies (Cronbach \& Gleser, 1957). Sechrest (1963) argued that a psychological test that was intended for applied use (i.e., academic, clinical, or personnel applications) must yield an improvement in prediction compared with the result derived from using data that are easily and routinely obtained as part of the process of assessment. This requirement presents a rather stringent test of validity (Hunsley \& Meyer, 2003).

The Risks and Consequences Questionnaire (RCQ) is a 26-item questionnaire that fills this void. The adolescent is asked 1 ) how many times the risky behavior or consequence occurred, 2) the number of times it occurred with alcohol involved, and 3) the number of times it occurred with marijuana involved. Some items target consequences of substance use (missed time from school), whereas others assess risky behaviors related to use (willing rode in a car with someone who was driving dangerously). The RCQ adds to existing adolescent substance use instruments in the following ways: 1) It assesses the frequency of risky behaviors and consequences related to substance use; 2) it does so specifically for ethnically diverse incarcerated populations; 3 ) on a single instrument, it efficiently assesses for the target behavior, the relationship of alcohol to the behavior, and the relationship of marijuana to the target behavior; and 4) it is validated using rigorous methodology that has not been utilized in the validation of the above instruments. Moreover, due to time constraints and limited resources often evident in juvenile correctional facilities, the ease of the administration of the RCQ makes it suitable for use in this environment. The current study aims to validate this measure with a racially and ethnically diverse sample of incarcerated adolescents. Specific aims include assessing internal validity and concurrent and predictive incremental validity. 


\section{Methods}

\subsection{Participants}

The participants in this study were 175 adjudicated youth residing in a state juvenile correctional facility. The youth in the facility were sentenced for committing crimes ranging in severity from truancy to murder. Approximately 1,100 adolescents are detained at this facility annually. Of these, 500 to 600 of the youth are adjudicated and serve sentences at the facility, which estimates its annual recidivism rate to be $35 \%$. The youth receive both individual and group interventions, as needed, that address a range of problem behaviors (i.e., drug dealing, sex offending, crime reduction, anger management). A large number of youth also participate in an eight week psycho-educational group treatment for substance use/abuse that meets biweekly for one hour. Medical, dental, and psychiatric services are available, and the adolescents attend the facility's school. More in-depth substance abuse services are available as indicated, and traditional 12-Step groups (i.e., Alcoholic Anonymous) are also available weekly. Many of the youth in the facility are also involved with community religious organizations. Limited vocational programming and transitional services such as substance use counseling, case management, and mentoring are available for these youth.

The sample was $89.1 \%$ male with a mean age of $\underline{\mathrm{M}}=17.08$ years (standard deviation or $\underline{\mathrm{SD}}=$ 1.12). Approximately $28.6 \%$ of the adolescents are African American, $28.6 \%$ Hispanic, $34.3 \%$ Caucasian, $8.6 \%$ self-identified as "Other." The youth in this study had been previously detained, on average, $\underline{M}=2.70$ times $(\underline{S D}=3.35$; median $=2$; mode $=0)$ prior to their current incarceration. About $65.1 \%$ met criteria for life-time diagnosis of an alcohol use disorder, and for marijuana this figure is $92.6 \%$ (see description of SCID-I below).

\subsection{Procedures}

2.2.1 Screening and consent-Shortly upon adjudication, eligible youth were identified by the facility staff as potential participants for a larger treatment outcome study, of which the current study is a component, if they met the following criteria: Were between 14 and 19 years old, inclusive, and were to serve a four to twelve month sentence. If the youth agreed to participate, consent was obtained from the legal guardian or from those adolescents who were $\geq 18$ years old. The participants and guardians were informed that all disclosed information would be kept completely confidential with the exceptions of plans to escape, plans to hurt self or others, or reported cases of child abuse.

Participating adolescents were included in the study if they met any of the following substance use screening criteria: 1) In the year prior to incarceration they 1a) used marijuana or drank regularly (at least monthly), or $1 \mathrm{~b}$ ) they binge-drank ( $\geq 5$ standard drinks for boys; $\geq 4$ for girls) at least once; 2 ) they used marijuana or drank in the 4 weeks before the offense for which they were incarcerated; or 3) they used marijuana or drank in the 4 weeks before they were incarcerated. These screening criteria were based on national survey data (see for example, Johnston, O'Malley, \& Bachman, 2007; Federal Trade Commission, 2007; U.S. Dept. of Justice, 1999; Hser, Grella, Hubbard, Hsieh, Fletcher, Brown \& Anglin, 2001). The Institutional Review Board approved all of the procedures utilized. Adolescents were screened as research treatment staff had openings to see them. Of the 199 youth introduced to the study, 186 met the screening criteria; and 177 out of 186 completed the consent procedure. Of those 177 , two teens dropped out of the study prior to completing the initial assessment, leaving 175 adolescents enrolled at baseline. During follow-up assessment after release from the facility, $170(97.1 \%)$ adolescents were located for assessment. Variations in the number of participants involved in analyses are explicated in the Results section. 
2.2.2 Assessments-The baseline assessment consisted of a 90-minute interview by a trained Bachelors (BA) or Masters (MA)-level staff member. Three-month follow-up interviews lasted for 60-minutes and were conducted in the community, following release from the facility. Interviewers had at least 20 hours of training with one hour of individual and 1 hour of group supervision per week. In-vivo observations were conducted regularly by a Doctoral (PhD)-level project member. All assessment data were reviewed by a MA- or PhDlevel project member. Assessments occurred at baseline, which was shortly after adjudication, and at 3-months following release from the facility. Adolescents received snacks during assessments and a $\$ 50$ gift certificate for completion of the study.

\subsection{Measures}

2.3.1 Background Questionnaire (BGQ)—Socio-demographic information was recorded and included age, gender, and race/ethnicity.

2.3.2 Timeline Follow-back (TLFB)—Time-line Follow-back is a calendar-assisted approach that measures participants' recollection of their substance use over a specified period of time (Sobell \& Sobell, 1992). It has been used to assess alcohol use (Bardone, Krahn, Goodman, \& Searless, 2000; Sobell \& Sobell, 1992), drug use (Midanik, Hines, Barrett, Paul, Crosby, Stall, 1998), smoking (Lewis-Esquerre, Colby, Tevyaw, Eaton, Kahler \& Monti, 2005), binge eating (Bardone et al, 2000) and sexual behavior (Midanik et al., 1998). TLFB has been shown to have excellent reliability ( $\underline{\alpha} \mathrm{s}=.79$ to .98 ; Sobell, Maisto, Sobell \& Cooper, 1979 ) and strong content, criterion, and construct validity. A ninety day TLFB measuring marijuana and alcohol use was collected at baseline and at follow-up after release.

2.3.3 Structured Clinical Interview for DSM-IV (SCID-I)—The diagnostic interview modules for alcohol and marijuana abuse and dependence were administered (First, Gibbon, Spitzer, \& Williams, 1996).

2.3.4 Misbehaviors Questionnaire (MBQ)-This 40-item questionnaire is based on the work of Dembo and colleagues (1992a; 1993), the work of Elliott, Ageton, Huizinga, Knowles \& Canter (1983), and on symptoms of conduct and antisocial personality disorders as found in the Diagnostic and Statistics Manual of Mental Disorders-IV (American Psychiatric Association; 1994). At baseline, adolescents are asked the number of times each crime or misbehavior has been committed over the 12 months prior to incarceration. Similarly, adolescents are asked the number of times each was committed while under the influence of alcohol or in order to get alcohol, and this is repeated for marijuana. These behaviors range from truancy to forced sexual activity. Ages at which each misbehavior was first committed and most recently committed are recorded as is whether the activity was ever done without substances involved. A checklist for conduct disordered symptoms was developed from this questionnaire. At follow-up after release, the time period covered is 3 months since incarceration.

2.3.5 Risks and Consequences Questionnaire (RCQ)-This 26-item questionnaire is based upon the work of Dembo, Williams, Wothke \& Schmeidler (1992b) as well as several questionnaires (Customary Drinking and Drug Use Record by Brown et al, 1998; TeenAddiction Severity Index by Kaminer et al, 1991; Drinking and Driving Questionnaire by Donovan, 1993; Adolescent Injury Checklist by Starfield and colleagues, 1995 and Jelalian Spirito, Rasile, Vinnick, Rohrbeck \& Arrigan, 1997). At baseline, adolescents are asked the number of times each risky behavior or consequence occurred over the 12 months prior to incarceration. Similarly, adolescents are asked the number of times each occurred while under the influence of alcohol, or in order to get alcohol, or due to after-effects of alcohol. This is repeated for marijuana. It assesses sexual behavior, driving, injuries, fighting, school/work 
problems, family/peer issues, being a victim of crime, and suicide. Two items were not considered for analyses since their format was dissimilar as compared to the other 24 items.

The RCQ is a measure of problems that can be associated with alcohol and marijuana use. Problems can be associated with acquisition, and immediate as well as after-effects of use. A general and comprehensive approach to measuring alcohol and marijuana-related negative events was chosen. Like the RAPI, RMPI and the CPQ-A, the RCQ assesses risky behaviors, negative consequences, and behaviors associated with acquisition. However, content of items is geared towards incarcerated adolescents. For example, although it is important if substance use is associated with passing out or illness (as would be determined during assessment for substance use disorder), items of the RCQ reflect behavioral and functional impact of use. Such specific information (i.e., missing school due to after-effects) may be more impactful for adolescents than general information (i.e., fainting or becoming physically ill). A copy of the questionnaire is found in the appendix ${ }^{1}$.

\subsection{Analyses}

Before conducting analyses, responses were examined for each item to determine distributional characteristics. Given the nature of the questions and the open-ended nature of the response options, a wide range of response options was available. This produced distributions that were highly variable across items with a high degree of skew and kurtosis. As a result, if an item was endorsed as occurring one or more times, it was coded as 1 ; if it was endorsed as not happening, it was coded as 0 . If the number of adolescents endorsing an item was $\underline{\mathrm{n}}<5$ for the entire sample, the item was removed (see Devellis, 2003).

Each endorsed dichotomized item was then correlated with the remaining item totals separately for alcohol and marijuana. Only items with correlations at 0.25 or more for both alcohol and marijuana were retained. Factor analysis (see details below) was then conducted on the remaining items to determine the number of factors to retain and the items per factor. Principal factors extraction is be performed on dichotomized data because this extraction technique is widely used and understood. Similarly, use of dichotomized data on scales is more transportable to practitioners, rather than using complex data transformations. While dichotomous items often result lower factor loadings and require more items to achieve reliability, they will generally yield results that are similar to those found with rating scales (Clark \& Watson, 1995). Because dichotomous data are used with principal factors extraction, several indices are utilized to examine whether results are meaningful. These include Bartlett's (1954) test of sphericity, Kaiser's $(1970 ; 1974)$ measure of sampling adequacy, and analyses are re-run using principal components analysis to determine if results are duplicated. Following this, internal consistencies and test-retest reliabilities were obtained, and a series of hierarchical regressions were conducted to determine concurrent and predictive incremental validity of scales. During hierarchical regression, we entered a set of predictors into steps 1 - 2 of the regression, and then in step 3 the RCQ scale was entered in order to determine if it added significantly to the regression analyses above and beyond preceding steps.

\section{Results}

All variables were checked for distributional assumptions and transformed as needed (one outlier was recoded on "number of days drank in the 3 months after release"). Items 6 (Nearly drowned) and 22 (Trouble at work) were removed because the number of teens endorsing each of these items was $\underline{\mathrm{n}}<5$ for alcohol and marijuana; item 4 (Injured while playing sports) was removed because $\underline{\mathrm{n}}<5$ for alcohol, and we sought to retain parsimony across scales. Next each

\footnotetext{
${ }^{1}$ The Appendix is available with the online version of this paper at doi:xxx/j.drugalcdep.xxx ...
} 
dichotomized item was correlated with the remaining item totals for alcohol and then for marijuana. In order to retain parsimony across scales, we retained only those items with $\underline{r}>$ 0.25 for both scales (see Table 1).

Factor analysis (principal factors extraction with varimax rotation) was then conducted on the remaining 11 alcohol-related items. The scree plot (factors, in descending order, along the horizontal axis; eigenvalues along the vertical; see Cattell, 1966) suggested 1 factor be retained (very steep descending slope between factors 1 and 2, with a noticeable level slope beginning with factor 2), whereas the Kaiser (1960) rule suggested 3 factors be retained (that is, 3 factors with eigenvalues greater than 1). Rotated factor-loadings were examined, since this makes interpretation easier when there is more than one factor. The 3 -factor solution produced factors of 1-4 items across scales, leading to poor internal consistencies, therefore 1-factor solutions were retained for alcohol and marijuana scales. Similar procedures were conducted for the marijuana-related items with similar results. Table 2 shows the loadings for the single factor scales for alcohol and marijuana. Since loadings on one or both items are in the 0.4 range or above (see Stevens, 1986) all items were retained. With 11 items, $\underline{N}=175$, and average loadings of $0.521-0.528$, these scales are likely to replicate in other samples (Guadagnoli \& Velicer, 1988; Velicer, LaForge, Levesque \& Fava, 1994). Items 2 (cut) and 18 (missed time from school) were considered for removal; however, elimination did not substantially improve internal consistencies and in fact, removing them reduced internal consistencies slightly for the alcohol and marijuana scales. Internal consistencies for the alcohol RCQ (RCQ-A) and the marijuana RCQ (RCQ-M) were 0.794 and 0.801 , respectively.

Because dichotomous data were used with principal factors extraction, several indices were utilized to examine whether results are meaningful. Bartlett's (1954) test of sphericity was examined and results are highly significant ( $\mathrm{p}<0.001$ for both alcohol and marijuana), indicating adequate correlation matrices for the factor analytic techniques utilized. Kaiser's $(1970 ; 1974)$ measure of sampling adequacy approached 1 (in fact they are over 0.810 for alcohol and marijuana), indicating the data were more than adequate for the techniques employed ( $\geq 0.6$ is required for good factor analysis). Finally, analyses were re-run using principal components analysis and results were duplicated.

For the remaining analyses, average RCQ scores are used (items coded as 1 are totaled, then the sum is divided by 11). Test-retest stabilities for RCQ-A and RCQ-M were obtained comparing scores from the assessment provided at the start of incarceration to scores obtained covering the 3 months after release from incarceration. The average number of days between

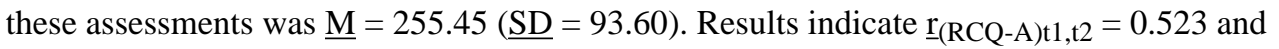
$\underline{\mathrm{r}}_{(\mathrm{RCQ}-\mathrm{M}) \mathrm{t} 1, \mathrm{t} 2}=0.504$. Correlations between RCQ-A and RCQ-M were also calculated at each time period: $\underline{\mathrm{r}}_{(\mathrm{RCQ}-\mathrm{A}, \mathrm{RCQ}-\mathrm{M}) \mathrm{t} 1}=0.631$ and $\underline{\mathrm{r}}_{(\mathrm{RCQ}-\mathrm{A}, \mathrm{RCQ}-\mathrm{M}) \mathrm{t} 2}=0.638$. The internal consistencies for RCQ-A and RCQ-M after release were 0.722 and 0.825 , respectively. Basic descriptive statistics at initial and follow-up assessments are as follows: $\underline{\mathrm{M}}_{\mathrm{RCQ}-\mathrm{A}, \mathrm{t} 1}=0.27$, $\underline{\mathrm{SD}}_{\mathrm{RCQ}-\mathrm{A}, \mathrm{t} 1}=0.24, \underline{\mathrm{M}}_{\mathrm{RCQ}-\mathrm{A}, \mathrm{t} 2}=0.09, \underline{\mathrm{SD}}_{\mathrm{RCQ}-\mathrm{A}, \mathrm{t} 2}=0.15 ; \underline{\mathrm{M}}_{\mathrm{RCQ}-\mathrm{M}, \mathrm{t} 1}=0.44, \underline{\mathrm{SD}}_{\mathrm{RCQ}-\mathrm{M}, \mathrm{t} 1}=$ $0.27, \underline{\mathrm{M}}_{\mathrm{RCQ}-\mathrm{M}, \mathrm{t} 2}=0.17, \underline{\mathrm{SD}}_{\mathrm{RCQ}-\mathrm{M}, \mathrm{t} 2}=0.22$.

Next, concurrent incremental validity was examined using data obtained during the assessment at the start of incarceration (see Table 3). A series of hierarchical regressions was conducted to predict a number of relevant dependent variables (DVs). Of interest was whether Step 3 (RCQ-A) of the regression procedure added incrementally to the amount of variance accounted for by the other independent variables (IVs). Specifically, although conduct disorder, substance dependence symptoms, and substance use should be related in this sample (see Stein et al, 2008), RCQ scales should provide information above and beyond these commonly related variables. For example, in the first regression procedure, $\mathrm{DV}_{1}=$ Conduct disorder symptom count in the 12 months before incarceration; Step 1 included demographic covariates $\left(\mathrm{IV}_{1}=\right.$ 
Age and Sex); Step 2 included $\mathrm{IV}_{2}=$ Number of days drank in the 3 months before incarceration; and Step $3\left(\mathrm{IV}_{3}\right)=\mathrm{RCQ}-\mathrm{A}$. As can be seen from Table 3, the RCQ-A added significantly $\left(\underline{F}_{c h}[1,162]=16.752, \underline{p}<0.001\right)$ to the prediction of $\mathrm{DV}_{1}$ (Conduct disorder symptom count in $12 \mathrm{mo}$. before incarceration) beyond the covariates and $\mathrm{IV}_{2}$ (Number of days drank in 3 mo. before incarceration). The change in the amount of variance for which the RCQ-A accounted was 0.087. The remainder of Table 3 illustrates that RCQ-A is a robust predictor. Even using the conservative Bonferroni correction (Howell, 1992) to control for family-wise error, results are still highly significant: $\underline{\alpha}=0.05 / 2$ for $\mathrm{DV}=$ Conduct disorder symptom count and for DV $=$ Life-time alcohol dependence symptom count; $\underline{\alpha}=0.05$ for DV $=$ Number days drank in the 3 months before incarceration. Table 4 reveals similar results for RCQ-M.

Predictive incremental validity is shown in Tables 5 and 6. DVs are measured at the assessment conducted 3 months after release. RCQ-A and RCQ-M are measured at the assessment conducted at the start of incarceration. All other variables are also measured at the start of incarceration, unless noted otherwise in the tables. Conduct disorder symptom count covering the 3 months after release was the DV in 4 sets of hierarchical regressions. Set 1 had step $1=$ Age, Sex; step 2 = No. days drank in 3 months after incarceration; step $3=$ RCQ-A. Set 2 had step 1 = Age, Sex; step $2=$ No. days drank in 3 months before incarceration; step $3=$ RCQ-A. Set 3 had step 1 = Age, Sex; step $2=$ Alcohol dependence symptom count-lifetime; step $3=$ RCQ-A. Set 4 had step 1 = Age, Sex; step $2=$ Conduct disorder symptom count in 12 months before incarceration; step $3=\mathrm{RCQ}-\mathrm{A}$. Therefore, employing the Bonferroni correction provides $\underline{\alpha}=0.05 / 4=0.0125$. Similarly, Number of days drank in the 3 months after release was the DV in 3 sets of regressions, and so $\underline{\alpha}=0.05 / 3=0.0167$ (see Table 5 for the 3 sets). To conserve space, only significant results are shown (nonsignificant results are available upon request from the first author). The RCQ-A offered no incremental predictive validity in predicting the conduct disorder DV, but as can be seen from Table 5, it was a robust predictor of drinking after release.

Table 6 reveals that RCQ-M significantly predicts Conduct disorder symptom count after release beyond Number of days used marijuana in the 3 months before incarceration and beyond Alcohol dependence symptom count. The other two sets of regressions predicting the conduct disorder DV were not significant after applying the Bonferroni correction and are not presented (but again, results are available from the first author upon request): Set 1 had step $1=$ Age and Sex, step $2=$ No. days used marijuana in 3 months after incarceration, step $3=$ RCQ-M; Set 2 had step $1=$ Age and Sex, step $2=$ Conduct disorder symptom count in 12 months before incarceration, step $3=$ RCQ-M. Table 6 also shows that RCQ-M is a robust predictor of marijuana use after release.

\section{Discussion}

Few measures exist to assess risky behaviors and consequences as they relate to substance use in juvenile delinquents. This study sought to validate such a measure on a racially and ethnically diverse sample. Results indicate that alcohol-related risky behaviors and consequences comprise a single scale as do marijuana-related risky behaviors and consequences. Furthermore, results suggest that the retention of common items for both scales produces reliable and valid scales and maintains parsimony. Internal consistencies were more than adequate $(0.72-0.83)$ and test-retest stabilities, even across several months were acceptable (0.52 - 0.50). Stabilities are noteworthy, given the time between testing (about 9 months), that adolescents received treatment between testing, and that time periods covered at each assessment point differed (12 months pre- vs. 3 months post-incarceration). 
The scales evidenced a very high degree of concurrent incremental validity in predicting conduct disorder above and beyond consumption patterns and dependence symptoms. They predicted dependence symptoms above and beyond consumption patterns and conduct disordered behaviors. Similarly, they predicted consumption patterns beyond conduct disordered behaviors.

The scales also evidenced a high degree of predictive incremental validity in that the RCQ scales as measured at the start of incarceration predicted relevant constructs months later after release from incarceration. RCQ scales predicted consumption patterns after incarceration above and beyond consumption patterns before incarceration and conduct disordered behaviors. The RCQ-A was not related to conduct disordered behaviors after incarceration; however, the RCQ-M did predict this DV above and beyond consumption patterns before incarceration and dependence symptoms.

These scales are primarily for researchers at this time. However, clinicians may consider using the 11-item scales by employing the directions as provided earlier in this paper (see Measures section). Items endorsed at 1 or more times are converted to 1 , and those not endorsed are coded as 0 . For each scale (RCQ-A and RCQ-M) separately, items are then totaled, divided by 11 , and then multiplied by 100 in order to provide a percent. In this way, scores range from $0 \%$ to $100 \%$. Lower scores indicate few risky behaviors and consequences related to substance use, whereas higher scores indicate more risky behaviors and consequences related to substance use. As an example, feedback can then be provided to an adolescent that $\mathrm{s} / \mathrm{he}$ endorsed 55\% of items from a questionnaire measuring risky behaviors and consequences related to alcohol use, and that for marijuana use, s/he endorsed $73 \%$ of items. A more detailed discussion may then take place regarding which items were endorsed and how often they may come up in the adolescent's daily life.

Researchers can use these scales to measure a generalized construct tapping risks and consequences as related to alcohol and marijuana use. It should be administered as described in the Measures section, items can then be converted to 0's and 1's as described above, totaled, and divided by $11 \mathrm{in}$ order to develop a score ranging from 0.00 to 1.00 (conversion to percent is optional). Furthermore, researchers may wish to analyze data at the item level using nondichotomized responses (with appropriate non-parametric tests or transformations), depending on the needs of their research. Indeed the questionnaire has been used in this manner in several published studies (Stein, Colby, Barnett, Monti, Golembeske \& Lebeau-Craven, 2006; Rosengard, et al, 2006; Rosengard, Stein, Barnett, Monti, Golembeske, Lebeau-Craven \& Miranda, in press).

The RCQ may assist with measuring psychosocial problems related to alcohol and marijuana use, and provide information, but not replace structured interview, for making substance use diagnoses (indeed it would need to demonstrate adequate sensitivity and specificity to replace structured diagnostic interview). It may be used as an intervention outcome measure (perhaps in relation to individually tailored interventions) as well.

Interpretation of study findings should take into consideration the nature of the data. The data collected were primarily from self-reports and may have been influenced by social desirability or an attempt to inflate and/or minimize reports of various behaviors, including drug use. However, interviewers were specially trained to assure participants' confidentiality and interviews were conducted in confidential, unmonitored settings, both inside the facility and within the community. Recent research on the accuracy of adolescents' reports of sensitive behaviors (such as sexual behaviors) indicates good accuracy over moderate periods of time (e.g., 3 months) and using face-to-face interviewing (Durant \& Carey, 2000; Jaccard, McDonald, Wan, et al, 2002). Similarly, although self-report of substance use is also subject 
to under/over-reporting, it is one of the most sensitive indicators of substance use. Evidence generally supports accuracy of self-reports (Babor, Webb, Burleson, \& Kaminer, 2002). Teens appear to report more misbehaviors than their parents report for them and to self-report more marijuana use than is detected in urinalysis (Dennis, Titus, Diamond, Donaldson, Godley, Tims, et al, 2002).

Incremental validity analyses are likely not influenced by overlap in the content of items in the dependent and independent measures. Research assistants were trained and monitored to not double count items within a measure or across measures. Although there is one item involving speeding that may be answered in common when comparing the MBQ (engaged in activities that could be dangerous to self/others [speeding]) and RCQ (speeding, taking chances, accidents while driving), given this single item, it likely does not influence analyses.

This study has several limitations. Replication is needed in other correctional settings as well as in other settings such as outpatient and psychiatric settings. Although strengths of the study include an ethnically and racially diverse sample covering a wide age range, future studies may wish to include more girls. The equivalence of item performance across gender and ethnicity/ race is a topic for further study (the sample size, $\underline{N}=175$, precluded examination of response variations by race/ethnicity or gender). Similarly, older adult samples may be included and we recommend adding items with relevant themes (e.g., arguing with spouse/partner). Future studies may also wish to conduct follow-up validity studies in which more variation between alcohol and marijuana scales is allowed. There were several decision points that might have led to different item content between alcohol and marijuana scales. For example, item 4 (injured while playing sports) might have been retained for RCQ-M; as many as 7 more items might have been retained for the RCQ-A during the item-item total correlations step (see Table 1); and two items from the RCQ-A (cut; missing time from school) and 1 from the RCQ-M (cut) might have been eliminated during examination of factor loadings (see Table 2). We chose to retain parsimony between scales and so developed scales with common items. Such an instrument is relatively simple to administer, yet valid, in a fast paced environment with few resources. Although the scales presented here are valid and reliable, allowing for variation between scales in item content may have more utility in assessing the ways in which adolescents use alcohol and marijuana differently and suffer potentially different consequences.

The RCQ adds to existing adolescent substance use instruments. It is validated using rigorous methodology that has not been utilized in the validation of other similar instruments. It was created using an ethnically and racially diverse incarcerated adolescent sample. Moreover, due to time constraints and limited resources often evident in juvenile correctional facilities, the ease of the administration of the RCQ makes it suitable for use in this environment.

\section{Supplementary Material}

Refer to Web version on PubMed Central for supplementary material.

\section{References}

American Psychiatric Association. Diagnostic and Statistical Manual of Mental Disorders. 4th. Washington, DC: Donnelley \& Sons Company; 1994.

Babor TF, Webb C, Burleson JA, Kaminer Y. Subtypes of classifying adolescents with marijuana use disorders: Construct validity and clinical implications. Addiction 2002;97:58-69. [PubMed: 12460129]

Bardone AM, Krahn DD, Goodman BM, Searless JS. Using interactive voice response technology and timeline follow-back methodology in studying binge eating and drinking behavior: Different answers to different forms of the same question? Addictive Behaviors 2000;25(1):1-11. [PubMed: 10708315] 
Bartlett M. A note on the multiplying factors for various chi-square approximations. Journal of the Royal Statistical Society 1954;16:296-298.B

Brown SA, Myers MG, Lippke L, Tapert SF, Stewart DG, Vik PW. Psychometric evaluation of the Customary Drinking and Drug Use Record (CDDR): A measure of adolescent alcohol and drug involvement. Journal of Studies on Alcohol 1998;59:427-438. [PubMed: 9647425]

Cattell, R. The meaning and strategic use of factor analysis. In: Cattell, R., editor. Handbook of multivariate experimental psychology. Chicago: Rand McNally; 1966. p. 174-243.

Clark LA, Watson D. Constructing validity: Basic issues in objective scale development. Psychological Assessment 1995;7:309-319.

Copeland J, Gilmore S, Gates P, Swift W. The cannabis problems questionnaire: Factor structure, reliability and validity. Drug and Alcohol Dependence 2005;80(3):313-319. [PubMed: 15916867]

Cronbach, LJ.; Gleser, GC. Psychological tests and personnel decisions. Urbana: University of Illinois Press; 1957.

Dembo R, Schmeidler J, Borden P, Sue CC, Manning D. Use of the POSIT among arrested youths entering a juvenile assessment center: A replication and update. Journal of Child \& Adolescent Substance Abuse 1997;6(3):19-42.

Dembo R, Williams L, Schmeidler J, Berry E, Wothke W, Getreu A, Wish ED, Christensen C. A structural model examining the relationship between physical child abuse, sexual child victimization, and marijuana/hashish use in delinquent youth: A longitudinal study. Violence and Victims 1992a;7:4162. [PubMed: 1504033]

Dembo R, Williams L, Schmeidler J, Wothke W. A longitudinal study of the predictors of the adverse effects of alcohol and marijuana/hashish use among a cohort of high risk youths. International Journal of the Addictions 1993;28:1045-1083. [PubMed: 8407028]

Dembo R, Williams L, Wothke W, Schmeidler J. Examining a structural model of the relationships among alcohol use, marijuana/hashish use, their effects, and emotional and psychological problems over time in a cohort of high risk youths. Deviant Behavior: An Interdisciplinary Journal 1992b;13:185215.

Dennis M, Titus JC, Diamond G, Donaldson J, Godley SH, Tims FM, et al. The Cannabis Youth Treatment (CYT) experiment: Rationale, study design and analysis plans. Addiction 2002;97 (Supplement 1):16-34. [PubMed: 12460126]

DeVellis, RF. Scale development: Theory and applications. 2nd. Newbury Park, CA: Sage; 2003.

Donovan JE. Young adult drinking-driving: Behavioral and psychosocial correlates. Journal of Studies on Alcohol 1993;54:600-613. [PubMed: 8412150]

Durant LE, Carey MP. Self-administered questionnaires versus face-to-face interviews in assessing sexual behavior in young women. Archives of Sexual Behavior 2000;29(4):309-322. [PubMed: 10948721]

Elliot, DS.; Ageton, SS.; Huizinga, D.; Knowles, BA.; Canter, RJ. The prevalence and incidence of delinquent behavior: 1976-1980. Boulder, CO: Behavioral Research Institute; 1983.

Federal Trade Commission. Appendix A: Underage Alcohol Use and Risks. 2007. Retrieved July 23, 2009, http://www.ftc.gov/reports/alcohol/appendixa.shtm

First MB, Gibbon M, Spitzer RL, Williams JBW. User's Guide for the Structured Clinical Interview for DSM-IV Axis I disorders: Research version [SCID-I, Version 2.0, February 1996 FINAL Version]. 1996

Guadagnoli E, Velicer WF. Relation of sample size to the stability of component patterns. Psychological Bulletin 1988;103:265-275. [PubMed: 3363047]

Howell, D. Statistical methods for psychology. 3rd. Boston: PWS-Kent; 1992.

Hunsley J, Meyer G. The incremental validity of psychological testing and assessment: Conceptual, methodological, and statistical issues. Psychological Assessment 2003;15(4):446-455. [PubMed: 14692841]

Hser YI, Grella CE, Hubbard RL, Hsieh SC, Fletcher BW, Brown BS, Anglin MD. An evaluation of drug treatments for adolescents in 4 US cities. Archives of General Psychiatry 2001;58(7):689-695. [PubMed: 11448377]

Jaccard J, McDonald R, Wan CK, et al. The accuracy of self-reports of condom use and sexual behavior. Journal of Applied Social Psychology 2002;32(9):1863-1905. 
Jelalian E, Spirito A, Rasile D, Vinnick L, Rohrbeck C, Arrigan M. Risk-taking, reported injury, and perception of future injury among adolescents. Journal of Pediatric Psychology 1997;22:513-532. [PubMed: 9302849]

Johnston, L.; O'Malley, P.; Bachman, J. National Survey Results on Drug Use from the Monitoring the Future Study, 1975 - 2007. Volume I: Secondary School Students (NIH Pub. No. 08-6418A). Rockville, MD: National Institute on Drug Abuse; 2007. p. 707

Johnson V, White HR. An investigation of factors related to intoxicated driving behaviors among youth. Journal of Studies on Alcohol 1989;50:320-330. [PubMed: 2787875]

Kaiser H. The application of electronic computers to factor analysis. Educational and Psychological Measurement, 1960 1960;20:141-151.

Kaiser H. A second-generation Little Jiffy. Psychometrika 1970;35:401-415.

Kaiser H. An index of factorial simplicity. Psychometrika 1974;39:31-36.

Kaminer Y, Bukstein OG, Tarter RE. The Teen-Addiction Severity Index: Rationale and reliability. International Journal of the Addictions 1991;26:219-226. [PubMed: 1889921]

Lansford JE, Erath S, Yu Tianyi, Pettit GS, Dodge KA, Bates JE. The developmental course of illicit substance use from age 12 to 22: Links with depressive, anxiety, and behavior disorders at age 18 . Journal of Child Psychology and Psychiatry 2008;49(8):877-885. [PubMed: 18564069]

Latimer WW, Winters KC, Stinchfield RD. Screening for drug abuse among adolescents in clinical and correctional settings using the Problem-Oriented Screening Instrument for Teenagers. American Journal of Drug and Alcohol Abuse 1997;23(1):79-98. [PubMed: 9048149]

Lewis-Esquerre JM, Colby SM, Tevyaw TO, Eaton CA, Kahler CW, Monti PM. Validation of the timeline follow-back in the assessment of adolescent smoking. Drug and Alcohol Dependence 2005;79(1): 33-43. [PubMed: 15943942]

McClelland GM, Elkington KS, Teplin LA, Abram KM. Multiple substance use disorders in juvenile detainees. Journal of the American Academy of Child \& Adolescent Psychiatry 2004;43(10):12151224. [PubMed: 15381888]

Midanik LT, Hines AM, Barrett DC, Paul JP, Crosby GM, Stall RD. Self-reports of alcohol use, drug use and sexual behavior: Expanding the timeline follow-back technique. Journal of Studies on Alcohol 1998;59(6):681-689. [PubMed: 9811089]

Muilenburg J, Johnson W, Usdan S, Annang L, Clayton D. Prevalence of impaired driving behaviors in a diverse, rural, southern middle school. Accident Analysis \& Prevention 2007;39(6):1080-1087. [PubMed: 17920829]

National Center on Addiction and Substance Abuse at Columbia University. Columbia University; New York: 2004. Criminal neglect: Substance abuse, juvenile justice, and the children left behind. Retrieved February 9, 2008 from http://www.casacolumbia.org/Absolutenm/articlefiles/JJreport.pdf

Rahdert, ER. The adolescent assessment/referral system manual (DHHS Publication No. ADM91-1735). Rockville, MD: National Institute on Drug Abuse; 1991.

Riley A, Harris S, Ensminger M, Ryan S, Alexander C, Green B, et al. Behavior and injury in urban and rural adolescents. Injury Prevention 1996;2(4):266-273. [PubMed: 9346106]

Rosengard C, Stein LAR, Barnett N, Monti P, Golembeske C, Lebeau-Craven R. Co-occurring sexual risk and substance use behaviors among incarcerated adolescents. Journal of Correctional Health Care 2006;12(4):279-287. [PubMed: 19756249]

Rosengard C, Stein LAR, Barnett N, Monti P, Golembeske C, Lebeau-Craven R, Miranda R. Outcome of a randomized clinical trial: Reducing substance-related sexually risky behaviors in incarcerated adolescents. Journal of Correctional Health Care. in press.

Sechrest L. Incremental validity: A recommendation. Educational and Psychological Measurement 1963;23:153-158.

Sobell LC, Maisto SA, Sobell MB, Cooper AM. Reliability of alcohol abusers' self-reports of drinking behavior. Behavior Research and Therapy 1979;17:157-160.

Sobell, LC.; Sobell, MB. Timeline follow-back: A technique for assessing self-reported alcohol consumption. In: Allen, J.; Litten, RZ., editors. Measuring alcohol consumption: Psychosocial and biological methods. Totowa, NJ: Humana Press, Inc.; 1992. p. 41-72. 
Spirito A, Rasile D, Vinnick L, Jelalian E, Arrigan M. Relationship between substance use and selfreported injuries among adolescents. Journal of Adolescent Health 1997;21(4):221-124. [PubMed: 9304452]

Starfield B, Riley AW, Green BF, Ensminger ME, Ryan SA, Kelleher K, Kim-Harris S, Johnston D, Vogel K. The Adolescent Child Health and Illness Profile: A population-based measure of health. Medical Care 1995;33:553-566. [PubMed: 7739277]

Stein LAR, Colby S, Barnett N, Monti P, Golembeske C, Lebeau-Craven R. Effects of motivational interviewing for incarcerated adolescents on driving under the influence after release. The American Journal on Addictions 2006;15:50-57. [PubMed: 17182420]

Stein, LAR.; Hesselbrock, V.; Bukstein, O. Disruptive behavior disorders (conduct disorder and oppositional defiant disorder) and adolescent substance abuse. In: Kaminer, Y.; Bukstein, OG., editors. Adolescent substance abuse: Psychiatric comorbidity \& high risk behaviors. Binghamton, NY: Haworth Press; 2008.

Stevens, J. Applied multivariate statistics for the social sciences. Hillsdale, NJ: Lawrence-Erlbaum Associates; 1986.

Teplin L, Abram K, McClelland G, Dulcan M, Mericle A. Psychiatric disorders in youth in juvenile detention. Archives of General Psychiatry 2002;59:1133-1143. [PubMed: 12470130]

Teplin L, Elkington K, McClelland G, Abram K, Mericle A, Washburn J. Major mental disorders, substance use disorders, comorbidity, and HIV-AIDS risk behaviors in juvenile detainees. Psychiatric Services 2005;56:823-828. [PubMed: 16020814]

Tolou-Shams M, Brown L, Gordon G, Fernandez I. Arrest history as an indicator of adolescent/young adult substance use and HIV risk. Drug and Alcohol Dependence 2007;88(1):87-90. [PubMed: 17092660]

U.S. Dept. of Justice. 1998 Annual Report on Drug Use Among Adult and Juvenile Arrestees. Arrestee Drug Abuse Monitoring Program (ADAM). National Institute of Justice; Washington, DC: 1999.

Velicer WF, LaForge RG, Levesque DA, Fava JL. Development and initial validity of smoking policy invention. Tobacco Control 1994;3:347-355.

Whalen, L.; Grunbaum, J.; Kinchen, S.; McManus, T.; Shanklin, S.; Kann, L., et al. US Dept. of Health and Human Services: Centers for Disease Control and Prevention; 2006. Middle school youth risk behavior survey 2003-Full report. Retrieved February 9, 2008 from http://www.cdc.gov?Healthyyouth/yrbs/middleschool2003/pdf/narrative.pdf

White HR, Labouvie EW. Towards the assessment of adolescent problem drinking. Journal of Studies on Alcohol 1989;50(1):30-37. [PubMed: 2927120]

Winters, KC. Bethesda, MD: National Institute of Alcohol Abuse and Alcoholism of the National Institute of Health; 2004. Assessment of alcohol and other drug use behaviors among adolescents. Retrieved May 29, 2008, from http://pubs.niaaa.nih.gov/publications/Assesing\%20Alcohol/behaviors.htm

Winters, KC.; Henly, GA. Personal Experiences Inventory and Manual. Los Angeles: Western Psychological Services; 1989.

Drug Alcohol Depend. Author manuscript; available in PMC 2011 June 1. 
Table 1

Item-Item Total Correlations.

\begin{tabular}{|c|c|c|c|}
\hline \multirow[t]{2}{*}{ Item } & \multicolumn{2}{|c|}{ Item Total Correlations ${ }^{a}$} & \multirow[t]{2}{*}{ Retained } \\
\hline & $\underline{\text { Alcohol }}$ & Marijuana & \\
\hline 1. Injured in a fight. & $0.327^{b}$ & $0.201^{c}$ & \\
\hline 2. Cut. & $0.346^{b}$ & $0.308^{b}$ & $\mathrm{Y}$ \\
\hline 3. Injured in a fall. & $0.274^{b}$ & $0.246^{c}$ & \\
\hline 5. Injured by a gun. & 0.117 & $0.192^{c}$ & \\
\hline 7. Burned. & $0.267^{c}$ & 0.139 & \\
\hline 8. Hit by a vehicle while walking. & $0.190^{c}$ & 0.146 & \\
\hline 9. Sex with someone not known well. & $0.322^{b}$ & $0.244^{c}$ & \\
\hline 10. Sex with someone known well. & $0.428^{b}$ & $0.477^{b}$ & $\mathrm{Y}$ \\
\hline 11. Sex without a condom. & $0.588^{b}$ & $0.435^{b}$ & $\mathrm{Y}$ \\
\hline 12. Risky driving. & $0.369^{b}$ & $0.323^{b}$ & $\mathrm{Y}$ \\
\hline 13. Rode with a risky driver. & $0.482^{b}$ & $0.467^{b}$ & $\mathrm{Y}$ \\
\hline 14. Argued with family. & $0.366^{b}$ & $0.317^{b}$ & $\mathrm{Y}$ \\
\hline 15. Argued with friends. & $0.422^{b}$ & $0.327^{b}$ & $\mathrm{Y}$ \\
\hline 16. Argued with someone dating. & $0.484^{b}$ & $0.441^{b}$ & $\mathrm{Y}$ \\
\hline 17. Relationship ended. & $0.299^{b}$ & $0.311^{b}$ & $\mathrm{Y}$ \\
\hline 18. Missed time from school. & $0.286^{b}$ & $0.301^{b}$ & $\mathrm{Y}$ \\
\hline 19. Trouble at school. & $0.228^{c}$ & $0.275^{b}$ & \\
\hline 20. Bad grades. & $0.242^{c}$ & $0.229^{c}$ & \\
\hline 21. Missed time from work. & $0.262^{c}$ & $0.212^{c}$ & \\
\hline 23. Victim of crime. & $0.278^{b}$ & $0.281^{b}$ & $\mathrm{Y}$ \\
\hline 24. Considered suicide. & $0.258^{c}$ & $0.219^{c}$ & \\
\hline
\end{tabular}

Notes: Median $\underline{N}_{\text {alcohol }}=138 ;$ Median $\underline{N}_{\text {marijuana }}=160$ because only participants endorsing the item were included in the correlation. Items 6 (nearly drowned) and 22 (trouble at work) were removed because the number of teens endorsing each of these items was $\underline{n} \leq 5$ for alcohol and marijuana; item 4 (injured while playing sports) was removed because $\underline{\mathrm{n}} \leq 5$ for alcohol, and we sought to retain parsimony across scales. $\mathrm{Y}=\mathrm{Yes}$, retain item.

${ }^{a}$ Pearson product moment correlations;

$b_{\mathrm{p}} \leq 0.001 ;$

${ }^{c} \mathrm{p} \leq 0.05$ 


\section{Table 2}

Factor Analysis Loadings $(\underline{\mathrm{N}}=175)$.

\begin{tabular}{llll} 
Item & \multicolumn{2}{c}{ Loadings } \\
\hline & $\underline{\text { Alcohol }}$ & Marijuana \\
2. Cut. & 0.376 & 0.353 \\
10. Sex with someone known well. & 0.567 & 0.620 \\
11. Sex without a condom. & 0.789 & 0.591 \\
12. Risky driving. & 0.428 & 0.495 \\
13. Rode with a risky driver. & 0.642 & 0.578 \\
14. Argued with family. & 0.517 & 0.548 \\
15. Argued with friends. & 0.603 & 0.617 \\
16. Argued with someone dating. & 0.646 & 0.631 \\
17. Relationship ended. & 0.421 & 0.403 \\
18. Missed time from school. & 0.323 & 0.424 \\
23. Victim of crime. & 0.424 & 0.543 \\
\hline
\end{tabular}




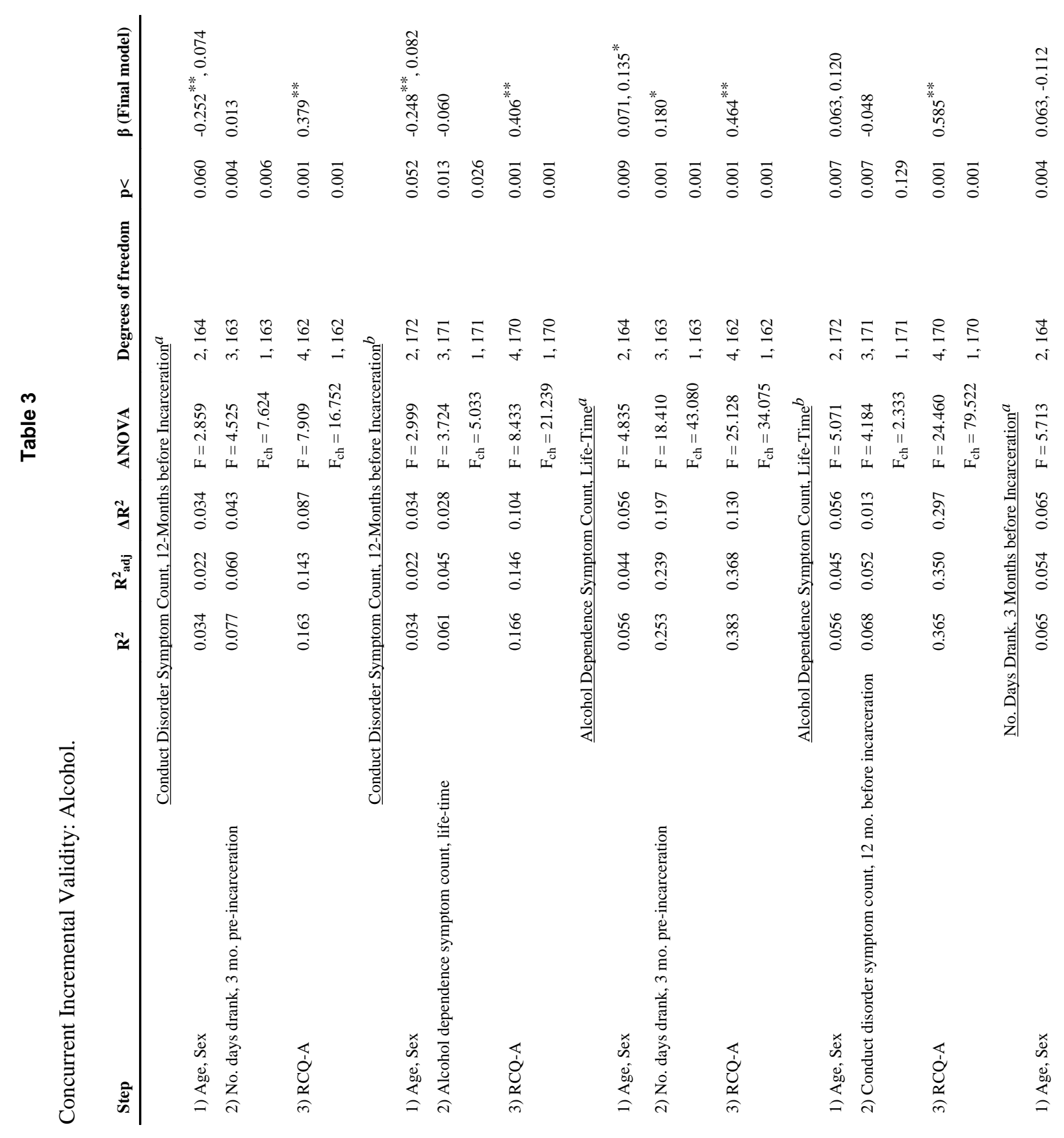

Drug Alcohol Depend. Author manuscript; available in PMC 2011 June 1. 


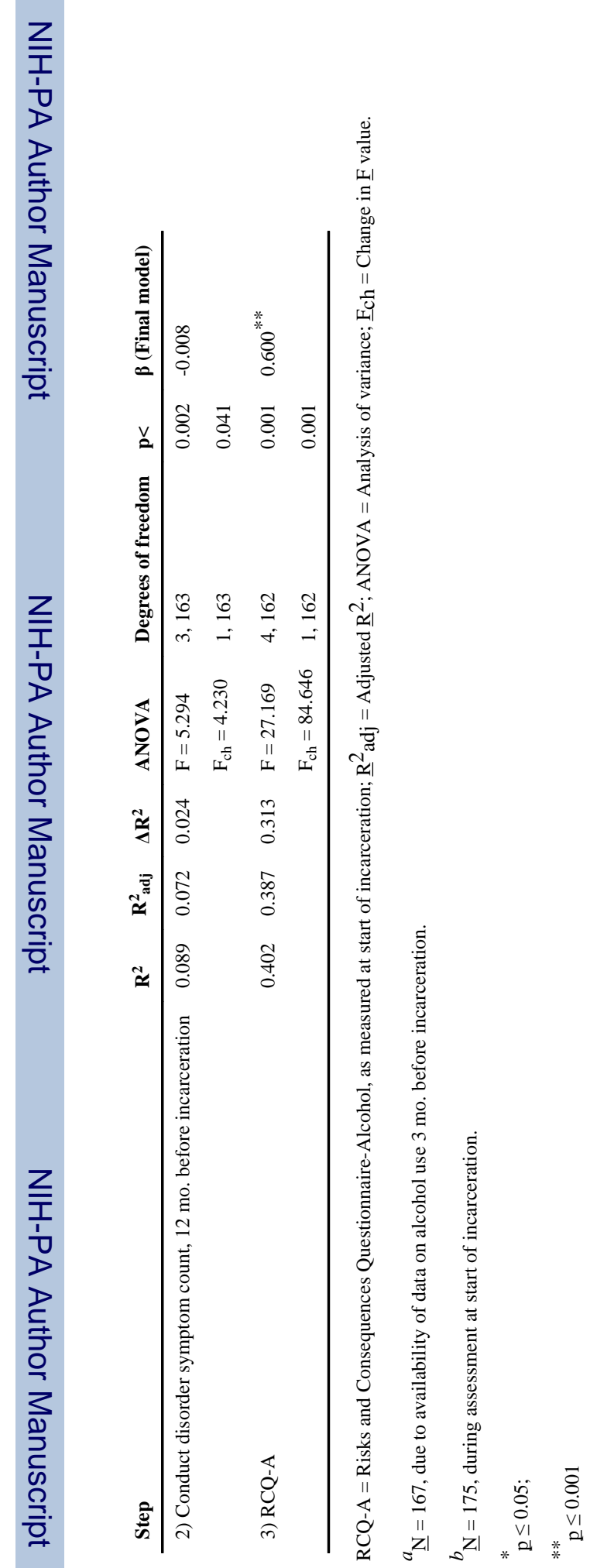




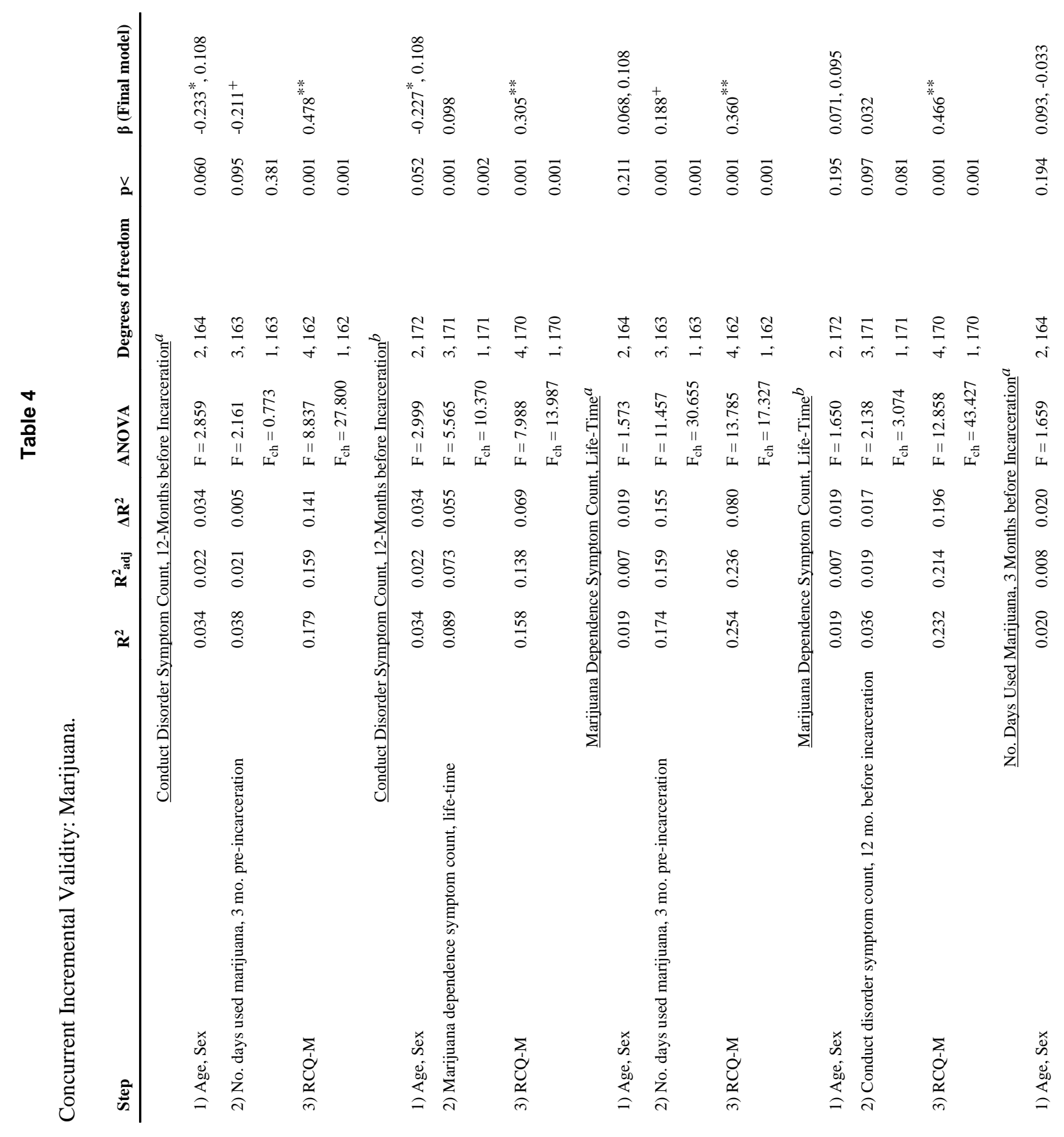




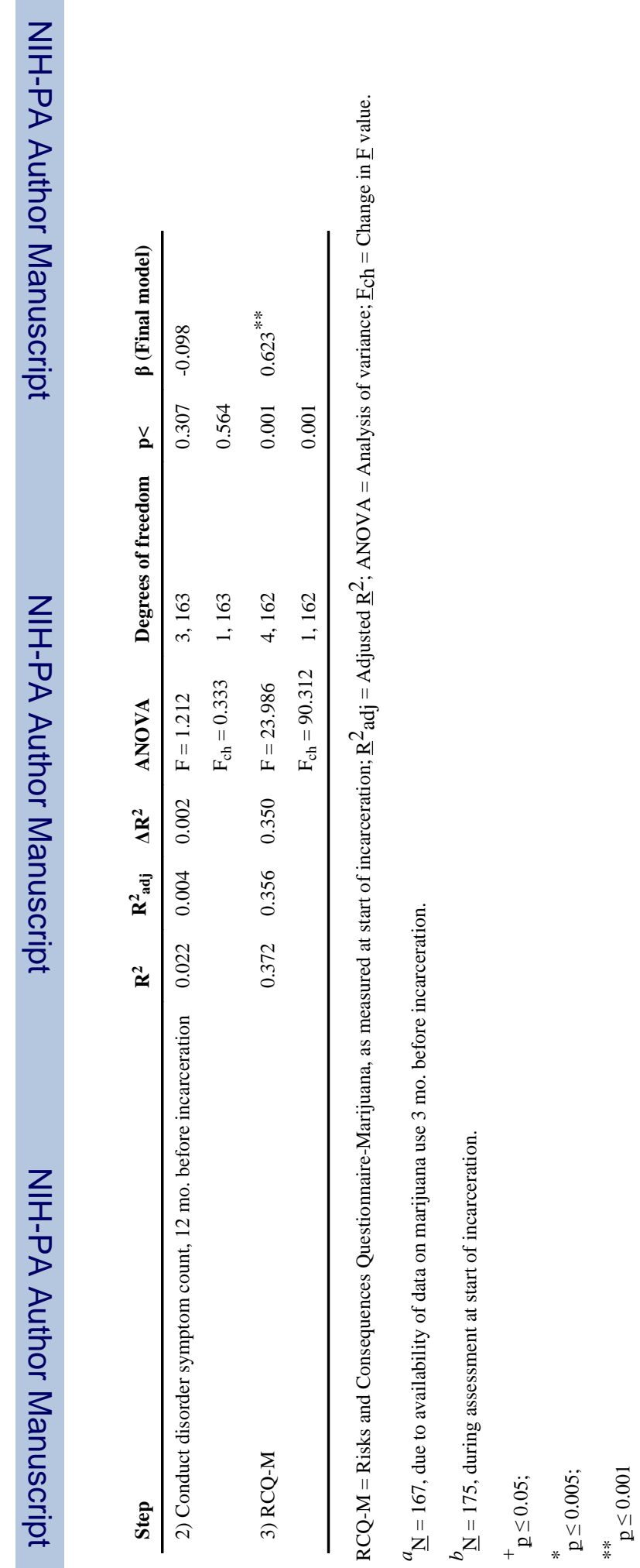




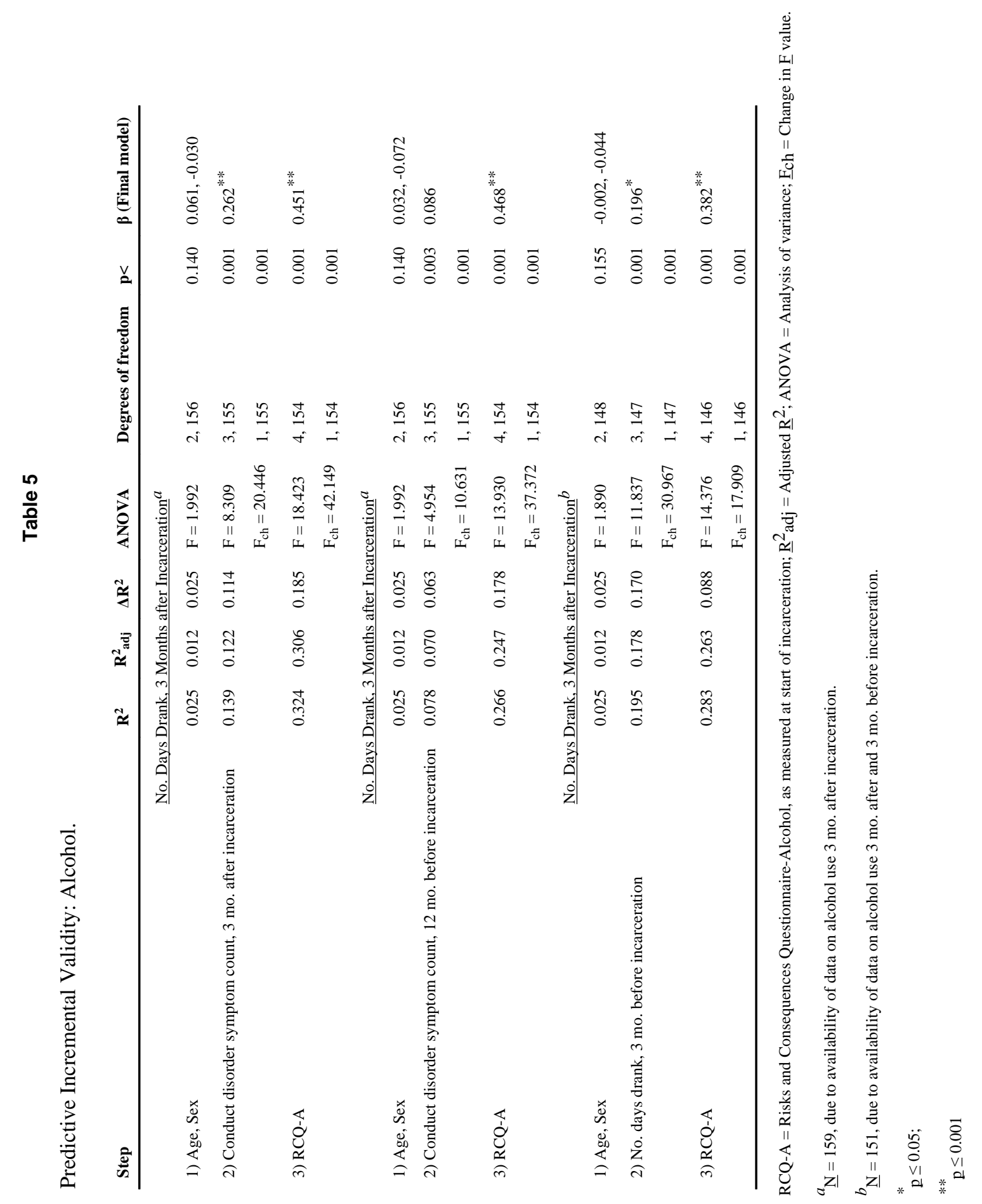




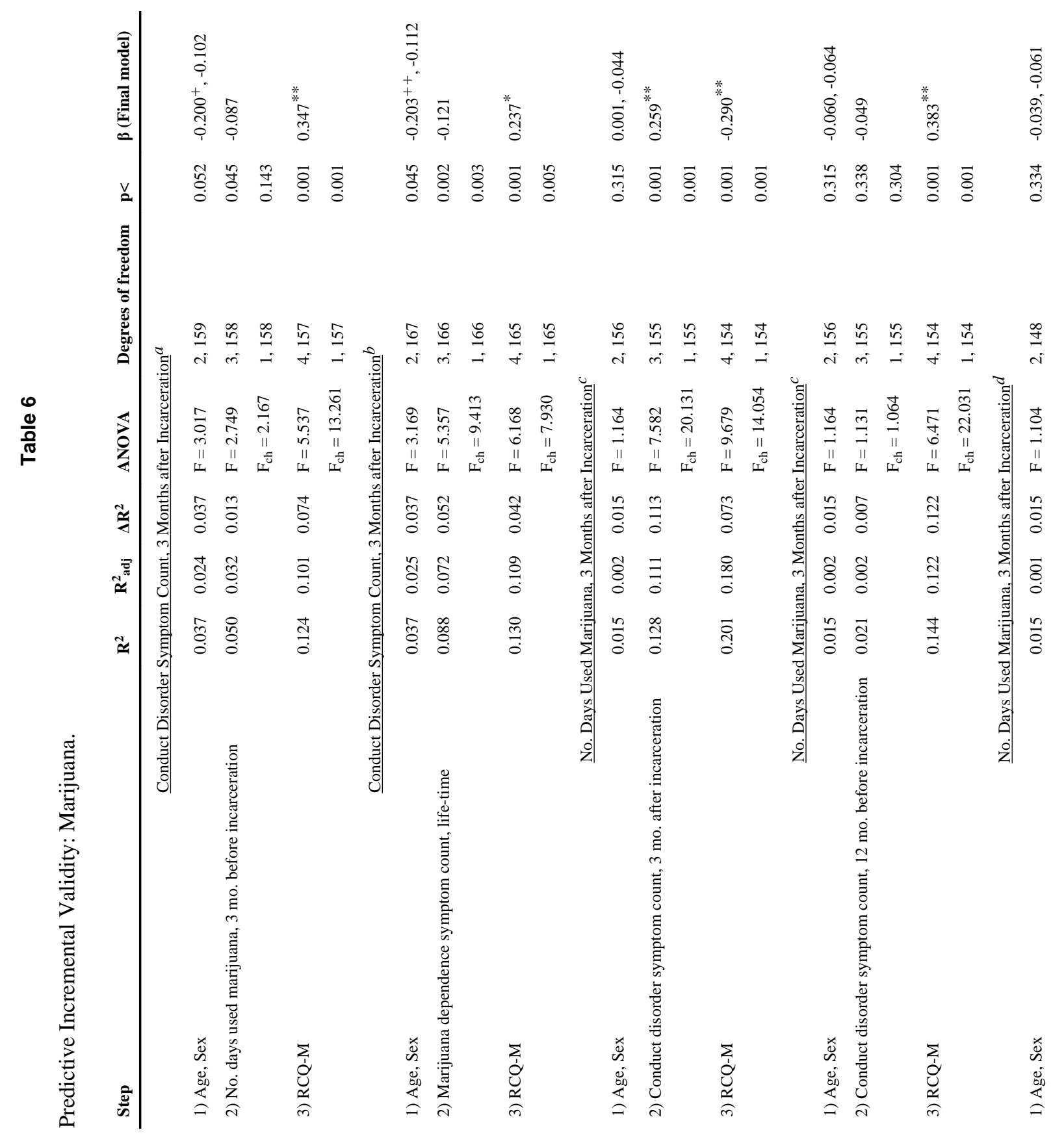

Drug Alcohol Depend. Author manuscript; available in PMC 2011 June 1. 


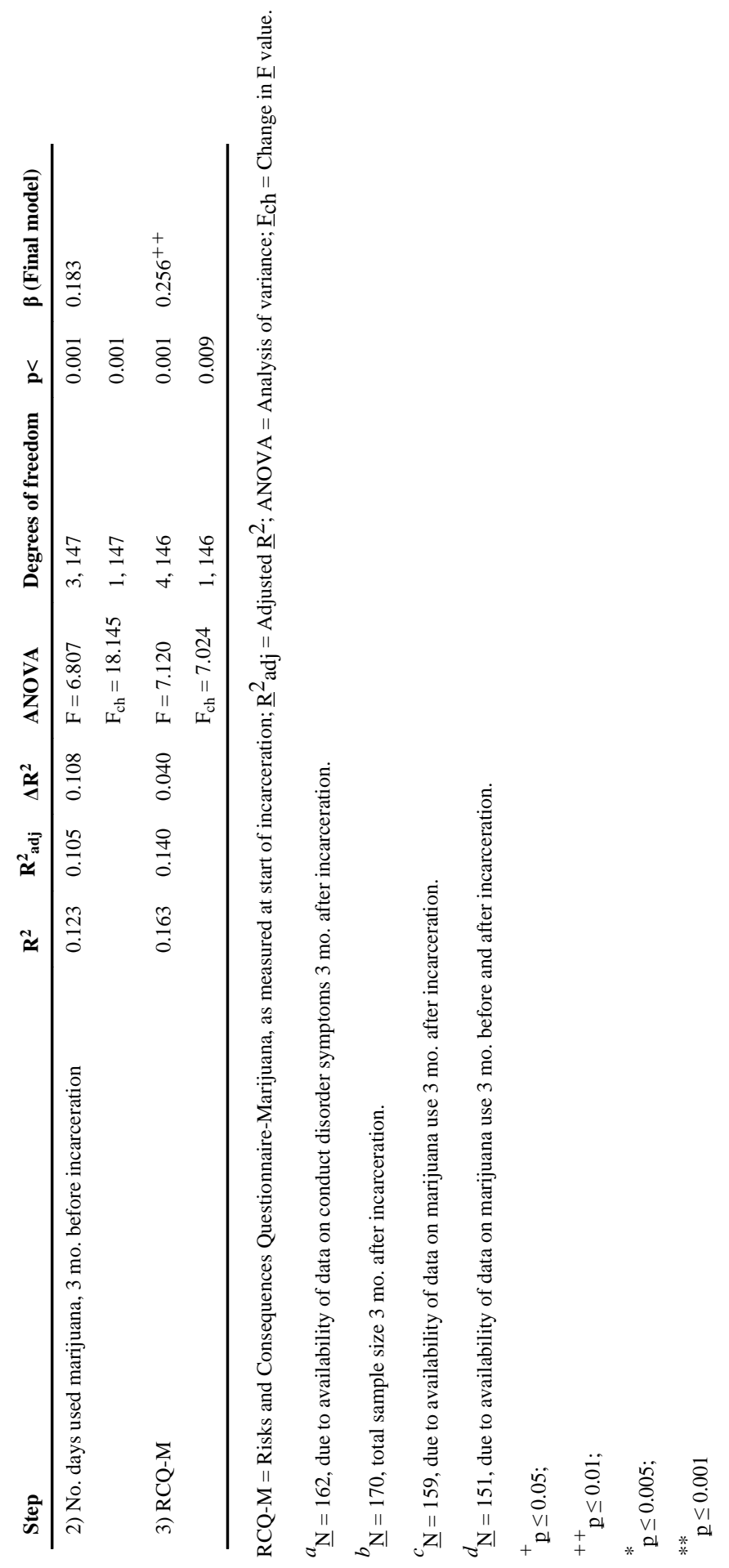

Drug Alcohol Depend. Author manuscript; available in PMC 2011 June 1. 